\title{
O Preconceito e as Diferenças na Literatura Infantil
}

\author{
Jully Fortunato Buendgens' \\ Diana Carvalho de Carvalho' \\ 'Universidade Federal de Santa Catarina (UFSC), Florianópolis/SC - Brasil
}

RESUMO - O Preconceito e as Diferenças na Literatura Infantil. O presente artigo analisa como o preconceito e as diferenças são tratados na literatura infantil destinada ao ensino fundamental pelo Programa Nacional Livro Didático de 2013. Fundamentado na Teoria Histórico-Cultural, analisou 14 obras que abordam as diferenças. A análise evidencia que as histórias apresentam sua trama na vida cotidiana, a principal esfera onde se origina o preconceito. As obras analisadas podem, em sua realização literária, contribuir para que o leitor crie outros sentidos às situações preconceituosas, tomando como referência as próprias experiências. Entretanto, é necessário discutir as diferenças pela sua dimensão histórica, considerando que elas são objetivadas nos processos desiguais da produção da vida.

Palavras-chave: Educação. Literatura Infantil. Preconceito. Diferenças. Programa Nacional do Livro Didático.

ABSTRACT - Prejudice and Differences in Children's Literature. This article discusses how prejudice and differences are approached in children's literature aimed at the K-12 education by the National Program of Schoolbook (Programa Nacional do Livro Didático-PNLD, 2013 edition). It is based on the Historical Cultural Theory. Fourteen literary works which deal with prejudice and/or differences were analyzed. In these books, daily life is the usual scenery and the main scope where prejudice originates. Children's literature should contribute to allow the readers to create other meanings to the prejudicial situations, using their own life experiences as reference. However, it is fundamental to discuss the differences by their historical dimension, considering that they are produced by unequal processes of production of life.

Keywords: Education. Children's Literature. Prejudice. Differences. National Program of Schoolbook.

Educação \& Realidade, Porto Alegre, v. 41, n. 2, p. 591-612, abr./jun. 2016. 591 http://dx.doi.org/10.1590/2175-623650721 


\section{Introdução}

Os debates sobre o preconceito e as diferenças estão cada vez mais presentes, tanto na esfera acadêmica quanto nos espaços escolares. Sob a perspectiva da Teoria Histórico-Cultural, entendemos que o preconceito é uma produção humana, estabelecida nas relações sociais e tem como base os meios desiguais de produção da vida. Nesse sentido, como um processo histórico, defendemos que é necessário abordá-lo sob uma perspectiva que compreenda o homem como sendo um sujeito histórico que se constitui socialmente e que modifica o mundo ao mesmo tempo em que se modifica.

Este artigo apresenta as principais discussões desenvolvidas durante a pesquisa de mestrado (Buendgens, 2014), que teve como objetivo investigar de que forma o preconceito e as diferenças são abordados nas obras de literatura infantil distribuídas nas salas de aula do ensino fundamental das escolas públicas pelo Programa Nacional do Livro Didático - PNLD de 2013.

A literatura infantil tem sido um meio cada vez mais utilizado pelos programas educacionais do governo para levar à sala de aula o debate sobre o respeito às diferenças. Esse tema é encontrado, tanto no Programa Nacional Biblioteca na Escola (PNBE) que encaminha acervos às bibliotecas das escolas públicas com livros de variadas temáticas e expressão literária, quanto no Programa Nacional do Livro Didático (PNLD) que, além dos livros didáticos, ainda envia às salas de aula acervos de literatura infantil para serem utilizados pelos professores e pelas próprias crianças (Buendgens, 2014).

Inicialmente, foi realizado um levantamento bibliográfico a fim de mapear as principais discussões acerca da temática investigada evidenciando que as pesquisas realizadas nos últimos cinco anos demarcam duas questões fundamentais: a escassez de investigações que utilizam como aporte teórico a Psicologia Histórico-Cultural; as diferenças, mais do que o preconceito, têm sido foco da maior parte das pesquisas. Tendo como referência as discussões realizadas por Vieira (2008), a qual afirma que as diferenças por elas mesmas não são produtoras de preconceito, sendo o preconceito um fenômeno objetivado em correspondência ao modo de produção da vida, pode-se inferir certa banalização em relação à discussão pretendida. Nesse sentido, ao tornar vulgar termos como diferenças e preconceito, é possível que discussões importantes que pautem a origem dos preconceitos sejam ofuscadas pelo excesso ou mau uso dessas palavras. Pensamos que o enfraquecimento de tais discussões tende a servir para reafirmar a conformação da hierarquia desigual que produz o preconceito, bem como para a manutenção do processo de alienação da vida cotidiana. 


\section{Preconceito como Forma de Cristalização da Estrutura e do Pensamento da Vida Cotidiana}

A partir da modernidade, as crianças deixam de ser vistas como adultos em miniatura e desenvolve-se um sentimento de infância. Essa nova criança passa a ser o centro-motor da vida familiar, sendo-lhe assegurado um espaço circundado por um sistema de cuidados e controle (Ariés, 2012). Em meio a essa nova configuração social, a escola moderna se consolida com o objetivo de disseminar ideias de civilidade e de uma nova moral. Com esta função, de educar as crianças e seu imaginário, Cambi (1999) indica o surgimento da literatura infantil que ocorreu inicialmente na França, por meio das fábulas e dos contos de fadas.

A infância passa a ter características próprias, com uma literatura própria, sendo que, com as fábulas e com os contos de fadas, estabelecem-se as condições para "[...] uma codificação e um controle do imaginário infantil, que desse modo é homologado e tornado dependente de uma série de normas e princípios que se inscreveram no horizonte do mundo burguês e que esses textos justamente podem difundir, confirmar e valorizar" (Cambi, 1999, p. 315). Desse modo, a literatura infantil surge atendendo a necessidade dessa nova escola para contribuir na formação do homem civil, no século XVII, fortemente vinculada a um caráter formador que atendia aos objetivos pedagógicos. Esse vínculo criou certa tensão "[...] entre o saber da obra literária (que diz apresento o mundo assim) e o ideal da pedagogia (que diz o mundo deveria ser assim). Tal tensão é o grande desafio da obra destinada ao público infantil que, não solucionado, muitas vezes abala o seu próprio estatuto literário" (Cademartori, 2010, p. 24, grifo do autor).

Assim como aconteceu com a literatura infantil na Europa, no Brasil a literatura para crianças também foi utilizada na formação de cidadãos, como divulgadora de valores ideológicos e moralizantes. Com o desenvolvimento das cidades, era necessário transformar uma sociedade rural em urbana e a escola teve papel fundamental na consolidação do projeto de um Brasil moderno. Essa intenção educativa acabou por levar, desde os contos clássicos, a silenciamentos nos livros infantis a respeito das discussões acerca das diferenças, de conflitos e de interesses dos jogos de poder, como demonstra Cademartori (2010, p. 25):

[...] tradicionalmente, a literatura infantil apresentou, por determinação pedagógica, um discurso monológico que, pelo caráter persuasivo, não abria brechas para interrogações, para o choque de verdades, para o desafio da diversidade, tudo se homogeneizando numa só voz. No caso, a do narrador.

Essa tendência acabou levando a literatura infantil a evitar, por muito tempo, o lado podre da sociedade, silenciando em seus títulos, tanto questões sociais, tais como sexualidade, conflitos de classes e 
diferenças raciais; quanto questões de âmbito existencial, ao fugir de problemas familiares, do tema da morte e das drogas. No entanto, a introdução de temas polêmicos, de conflitos e denúncias sociais pode desencadear, entre outras questões, "[...] a insistência numa visão adulta do problema, de modo que o texto se converte num manual de regras para a percepção da realidade circundante. Por esse aspecto, ele pode cair na mesma armadilha do didatismo que aflige grande parte da produção para a infância” (Zilberman, 2003, p. 188). Tal como explica a mesma autora, é preciso que tais temas sirvam de gatilho para o desenvolvimento de ações que os superem, a fim de que seja amenizada a influência adulta na percepção das questões sociais.

Bragatto Filho (1995) faz uma distinção importante entre texto literário, e o texto funcional, que é o texto não-literário, denominado assim pelo seu caráter pragmático. Os textos funcionais são aqueles que transmitem informações, solicitam algo, procuram convencer sobre alguma coisa ou ainda objetivam o ensino, como é o caso do texto didático. Por outro lado, o texto literário não se constitui a priori em um texto funcional, pois “[...] são os seus leitores que, a partir do diálogo com o mesmo, lhe atribuem diferentes funções ou finalidades" (Bragatto Filho, 1995, p. 14). O texto literário deixa brechas para serem preenchidas pelas crianças, num movimento que permite ao leitor aprender, refletir, comparar, questionar, investigar, transformar e adquirir cultura, ao entrar em contato com as mais diferentes visões de mundo.

Apesar de seu caráter formador presente desde sua origem, a literatura infantil quando realizada em sua função literária se transforma em um importante instrumento de emancipação e ruptura com o que está posto socialmente. Nesse sentido, quando a literatura infantil se compromete com o interesse da criança, “[...] transforma-se num meio de acesso ao real, na medida em que facilita a ordenação de experiências, pelo conhecimento de história, e a expansão de seu domínio linguístico" (Zilberman, 2003, p. 46). A literatura infantil, ao realizar-se em sua função artística, pode proporcionar ao seu destinatário uma concepção de mundo crítica e autônoma, possibilitando que a escola rompa suas limitações, inerentes à situação com a qual se comprometeu em sua origem. Segundo Zilberman (2003, p. 29), “[...] ela dá conta de uma tarefa a que está voltada toda a cultura - a de conhecimento do mundo e do ser, [...] o que representa um acesso à circunstância individual por intermédio da realidade criada pela fantasia do escritor”. E, mais do que apresentar o mundo à criança, a literatura infantil “[...] propicia os elementos para uma emancipação pessoal, o que é a finalidade implícita do próprio saber" (Zilberman, 2003, p. 29). Nessa perspectiva, o livro atua como propulsor de uma nova postura inquiridora e inconformada diante dos padrões instituídos.

Um texto autenticamente artístico constitui-se em um objeto formativo que pode ampliar e renovar o horizonte de percepção da criança. "E, se ela não reflete passivamente uma sociedade ou uma época, 
é porque expõe suas contradições, tornando patente suas fissuras, assim como as tentativas, por parte da classe dominante, de acobertá-las" (Zilberman, 2003, p. 175).

De acordo com Heller (2008), os preconceitos são produtos da vida e dos pensamentos cotidianos e decorrem de pensamentos ultrageneralizados, ou juízos provisórios, que se configuram, por um lado, quando “[...] assumimos estereótipos, analogias e esquemas já elaborados; por outro, eles nos são impingidos pelo meio em que crescemos e pode-se passar muito tempo até percebermos com atitude crítica esses esquemas recebidos, se é que chega a produzir-se tal atitude" (Heller, 2008, p. 64). Na vida cotidiana, a ultrageneralização é inevitável e refere-se sempre a um juízo provisório, pois “[...] se antecipa à atividade possível e nem sempre, muito pelo contrário, encontra confirmação no infinito processo da prática" (Heller, 2008, p. 64). Trata-se de uma tendência necessária à vida cotidiana, porque analisar todas as características em todas as situações, antes de efetivarmos uma ação, seria impossível. No entanto, vale destacar que nem todo juízo provisório é um preconceito, pois ele é um tipo particular de juízo. A diferença está na sua origem, a qual remete à estrutura da vida cotidiana.

Segundo Heller (2008, p. 72), os preconceitos “[...] são provocados pelas integrações sociais nas quais vivem os homens e, dentro dessas integrações, sobretudo pelas classes" e "[...] servem para consolidar e manter a estabilidade e a coesão da integração dada" (Heller, 2008, p. 76). Sendo assim, os preconceitos são produzidos principalmente nas classes dominantes, pois é a elas que interessa manter a coesão de sua estrutura. Com isso, os preconceitos são produzidos pela classe dominante, mesmo quando essa mesma classe, por meio das ciências, busca difundir ideias e ações de combate ao preconceito (Heller, 2008). Queremos dizer que, mesmo quando a classe dominante difunde um discurso de combate ao preconceito, ela não está isenta de ser produtora dos preconceitos aos quais se opõe. Heller (2008, p. 77) justifica tal situação, afirmando: "[...] as classes dominantes desejam manter a coesão de uma estrutura social que lhes beneficia" e ainda desejam "[...] mobilizar em seu favor inclusive os homens que representam interesses diversos".

Quanto ao fato da burguesia ser responsável pela maior parte dos preconceitos, Heller (2008) explica que isso ocorre pela necessidade de coesão da sociedade burguesa desde sua origem, a qual, diferentemente de outros regimes da Antiguidade ou do feudalismo clássico, sempre foi mais instável. Por isso a necessidade de veicular diferentes tipos de preconceitos de grupos, tais como os nacionais, raciais e étnicos. Isso não quer dizer que os preconceitos de grupos sejam produzidos pelo próprio estado de grupo e nem que, em períodos anteriores à burguesia, não existisse aversão ao diferente. Sobre isso, Heller (2008, p. 78, grifo do autor) afirma: “[...] o desprezo pelo outro, a antipatia pelo diferente, são tão antigos quanto a própria humanidade. Mas, até a sociedade burguesa, a mobilização de sociedades inteiras contra outras sociedades, 
O Preconceito e as Diferenças na Literatura Infantil

mediante sistemas de preconceitos, não constituiu jamais um fenômeno típico".

A produção de preconceitos decorre da cristalização das formas necessárias da estrutura e do pensamento da vida cotidiana e isso faz com que os indivíduos tenham reduzidas suas margens de movimentos, acarretando assim a alienação da vida cotidiana. Assim como a alienação, a produção dos preconceitos é determinada pelo sistema de produção, pela hierarquia da sociedade e pelo lugar que o indivíduo ocupa nessa sociedade. Segundo Heller (2008, p. 56), “[...] a alienação é sempre alienação em face de alguma coisa e, mais precisamente, em face das possibilidades concretas de desenvolvimento genérico da humanidade". De acordo com Vieira (2008, p. 12), “[...] a alienação, ao fazer-se presente na cotidianidade, abre larga passagem para a predominância de preconceitos, os quais são convertidos em uma espécie de óculos com os quais se olha, entende, explica e valida uma infinidade de situações vividas pelos indivíduos".

Para entender como o indivíduo se apropria dos elementos da cultura, tornando-os instrumentos importantes para operar no mundo em que vive, é preciso compreender o processo de desenvolvimento psicológico da criança. Vigotski (1989) afirma que se trata de um processo de natureza cultural, na qual ela irá apropriar-se, segundo suas possibilidades reais, das significações atribuídas pelos homens ao mundo, para passar da condição de ser biológico a ser humano. Isto é, o desenvolvimento cultural, mais do que inserir a criança na cultura, irá inserir a cultura na criança para assim torná-la um ser cultural (Pino, 2005). Assim, a cultura passa a ser constitutiva da natureza humana e isso ocorre por meio da mediação semiótica, a qual permite que a criança se aproprie do saber humano. Isso a capacita a interpretar o mundo e lhe dá condições para se comunicar com outras pessoas (Pino, 2005). Tal conceito é fundamental neste trabalho, pois, ao afirmar que as relações sociais implicam necessariamente na mediação semiótica, e considerando que o preconceito é produzido nessas relações, logo ele é mediado por signos. Com isso, entendemos por signo um meio inventado pelos homens para representar a realidade, tanto material quanto imaterial, a fim de poder compartilhar entre si o que se sabe a respeito dela (Pino, 2000). Desse modo, tanto a literatura infantil quanto os preconceitos são elementos da cultura, significados pelos Outros que, ao adquirirem significação para a criança, são apropriados por ela.

Leontiev (2004) também se dedicou ao tema da cultura ao discutir o desenvolvimento do psiquismo, demarcando diferenças entre os aspectos biológicos e sociais no ser humano e defendendo que o psiquismo é um produto da experiência humana social e histórica. Ou seja, o psiquismo humano se desenvolve por meio da apropriação da cultura material e simbólica, que foi produzida e acumulada pelo ser humano ao longo de toda a história da humanidade. Nesse sentido, o desenvolvimento humano é compreendido como um processo eminentemente de 
hominização, que não se submete às leis biológicas e que "[...] resultou da passagem à vida numa sociedade organizada na base do trabalho" submetida, assim, às leis histórico-culturais (Leontiev, 2004, p. 280).

No processo de apropriação da cultura, Vigotski indica como fundamentais os processos de imaginação e criação. Sobre a imaginação, Vigotski (2009, p. 22) esclarece: “[...] quanto mais rica a experiência da pessoa, mais material está disponível para a imaginação dela”. Tendo a imaginação sua origem no acúmulo de experiências da criança, podemos afirmar que a literatura infantil tem papel fundamental na transmissão desses conhecimentos, pois aumenta a quantidade de elementos da realidade à disposição da criança, ampliando suas experiências. Com isso, a,

[...] imaginação adquire uma função muito importante no comportamento e no desenvolvimento humanos. Ela transforma-se em meio de ampliação da experiência de um indivíduo porque, tendo por base a narração ou a descrição de outrem, ele pode imaginar o que não viu, o que não vivenciou diretamente em sua experiência pessoal (Vigotski, 2009, p. 25).

Ao considerar o papel da imaginação nos comportamentos humanos e a implicação da literatura infantil neste processo, constata-se que elas ampliam as possibilidades de ação da criança, pois a imaginação lhe permite acessar e assimilar novas experiências históricas e sociais que irão compor a própria atividade. A interdependência entre experiência e imaginação pode ser compreendida quando Vigotski (2009, p. 25) afirma que existe "[...] uma dependência dupla e mútua entre imaginação e experiência. Se, no primeiro caso a imaginação apoia-se na experiência, no segundo é a própria experiência que se apoia na imaginação".

Além das experiências prévias, as emoções também exercem importante papel na relação entre a atividade de imaginação e a realidade. Esse caráter emocional pode se manifestar por meio de sentimentos e emoções que tendem a se encarnar em imagens que acabam sendo relacionadas a um determinado sentimento. Conforme indica Vigotski (2009, p. 26), “[...] as imagens da fantasia servem de expressão interna dos nossos sentimentos" e "[...] propiciam uma linguagem interior para o nosso sentimento".

Considerando essa relação mútua entre emoção e imaginação, pode-se afirmar que os sentimentos também influenciam a imaginação. Vigotski chamou de lei da realidade emocional da imaginação a seguinte situação: mesmo que as construções fantasiosas não correspondam à realidade, elas provocam algo verdadeiro em nossos sentimentos. São suas palavras: “[...] qualquer construção da fantasia influi inversamente sobre nossos sentimentos e, a despeito de essa construção por si só não corresponder à realidade, todo sentimento que provoca é verdadeiro, 
realmente vivenciado pela pessoa, e dela se apossa" (Vigotski, 2009, p. 28). Assim, as imagens fantasiosas criadas pelas crianças ao lerem/ouvirem uma história infantil são irreais; no entanto, os sentimentos por elas vivenciados são verdadeiros. Esta lei psicológica pode ser a explicação do porquê algumas obras de arte, artefatos derivados da fantasia, exercerem forte ação em nós.

Ao considerar a influência de uma obra literária sobre os sentimentos da criança, percebemos a importância que os conteúdos presentes nos livros infantis podem ter para sua vida e atividades. Nesse sentido, o preconceito ou situações que o expressem, ao serem retratados nos livros infantis, permitem à criança vivenciar e sentir tais experiências, antes mesmo que elas aconteçam.

A construção da fantasia, mesmo que sobre algo novo e ainda não vivenciado pela criança, “[...] ao ser externamente encarnada, ao adquirir uma concretude material, essa imaginação cristalizada, que se fez objeto, começa a existir realmente no mundo e a influir sobre outras coisas" (Vigotski, 2009, p. 29, grifo do autor), e quando se cristaliza, torna-se realidade para a criança. Desse modo, “[...] ao se encarnarem, retornam à realidade, mas já com uma nova força ativa que a modifica. Assim é o círculo completo da atividade criativa da imaginação" (Vigotski, 2009, p. 30). Desse modo, a realidade na qual o livro infantil influi é aquela interna da criança, suas ideias, conceitos e sentimentos.

Mencionado isso, é legítimo dizer que cada indivíduo é singular e diferente, no entanto, os homens sob as relações de trabalho, condições e modos de vida existentes em nossa sociedade, não se constituem apenas como diferentes, mas sim como desiguais. Leontiev (2004, p. 293) explica que a desigualdade não decorre das diferenças biológicas naturais entre os seres humanos e afirma que "[...] ela é produto da desigualdade econômica, da desigualdade de classes e da diversidade consecutiva das suas relações com as aquisições que encarnam todas as aptidões e faculdades da natureza humana, formadas no decurso de um processo sócio-histórico”. Desse modo, não são as diferenças que produzem por si mesmas os preconceitos, enquanto a expressão do preconceito está sempre em correspondência com o modo de produção da vida.

Ante o exposto, podemos afirmar que, quanto mais desigualdade nos meios de produção da vida e no acesso à cultura, mais a vida cotidiana é alienada; e, quanto mais alienação, mais preconceitos são produzidos nas relações sociais. Nesse sentido, esclarece Heller (2008, p. 58): “[...] quanto maior for a alienação produzida pela estrutura econômica de uma sociedade dada, tanto mais a vida cotidiana irradiará sua própria alienação para as demais esferas”. Com relação às desigualdades que, como vimos, são promotoras dos preconceitos, Leontiev (2004, p. 295, grifo do autor) afirma:

É esta desigualdade que serve o mais das vezes para justificar uma distinção entre os representantes das raças 
superiores e inferiores. Os países onde se fazem os maiores esforços neste sentido são aqueles em que as classes dirigentes estão particularmente interessadas em dar uma justificação ideológica ao seu direito a submeter os povos menos avançados no seu desenvolvimento econômico e cultural.

Desse modo, as diferenças humanas que de fato existem são utilizadas como desculpas para encobrir e justificar as desigualdades, que estão relacionadas com a estrutura de produção da sociedade capitalista. Logo, o problema do preconceito não reside nas diferenças humanas, como nos quer fazer pensar a classe dominante; o problema é gerado pelos meios desiguais de produção da vida e apropriação da cultura. Ousamos afirmar que, mais do que falar sobre diferenças biológicas promotoras de preconceitos, devemos chamar a atenção para diferenças de possibilidades de apropriação da cultura.

Com relação às diferenças, Amaral (1998), ao desenvolver o conceito de significativamente diferente, nos ajuda a distinguir as simples diferenças, tal como preferência por uma cor, que embora sinalize uma dessemelhança, geralmente não são geradoras de situações conflitivas; das diferenças significativas, estas sim, bem mais complexas e comumente causadoras de embates. Esse conceito foi fundamental para a formulação do protocolo desenvolvido na pesquisa, bem como para as análises subsequentes. Segundo Amaral (1998, p. 13, grifo do autor) a diferença significativa, "[...] pressupõe a eleição de critérios, sejam eles estatísticos [...], de caráter estrutural/funcional (integridade de forma/ funcionamento), ou de cunho psicossocial, como o do tipo ideal".

Ao considerar a complexidade da nossa sociedade, afirmamos que a escola é lugar privilegiado para a transmissão às crianças da cultura acumulada na história da humanidade. Segundo Leontiev (2004, p. 291), “[...] quanto mais progride a humanidade, mais rica é a prática sócio-histórica acumulada por ela, mais cresce o papel específico da educação e mais complexa é a sua tarefa". E quanto mais complexa fica a sociedade, mais a escola é necessária à reprodução da cotidianidade e à produção e reprodução das esferas não-cotidianas. Dessa forma, a escola tem importante papel na formação do ser humano, enquanto mediadora do processo entre a vida cotidiana e não-cotidiana, ou seja, entre a transmissão dos conhecimentos acerca da linguagem, dos instrumentos e dos costumes e aqueles referentes às ciências, à filosofia, à arte, à política e à moral (Duarte, 2007). Segundo Duarte (2008, p. 33), em todas as esferas a apropriação da cultura assume sempre características de um processo educativo; no entanto, afirma: "[...] a educação escolar deve desempenhar um papel decisivo na formação do indivíduo" como processo que se diferencia "[...] qualitativamente das apropriações que ocorrem na vida cotidiana". 


\section{Percurso Metodológico}

Para analisar como as diferenças e os preconceitos são abordados na literatura infantil destinada às salas de aula dos anos iniciais do ensino fundamental pelo Programa Nacional do Livro Didático - PNLD de 2013 adotamos como base teórico-metodológica a abordagem materialista dialética da história humana. Nessa perspectiva, a análise psicológica deve versar sobre processos e não análise de fatos e objetos, pois estes são estáveis e fixos; a análise de processos "[...] requer uma exposição dinâmica dos principais pontos constituintes da história dos processos" (Vigotski, 2007, p. 62). Ou seja, ao analisar um processo buscamos explicar a gênese histórica do fato pesquisado, o que, segundo Pino (2005, p. 179), “[...] equivale a dizer que o procedimento metodológico é histórico-genérico, uma vez que o processo de gênese de um fato humano constitui a história desse fato".

Nesse sentido, nossa compreensão do preconceito vai ao encontro de nossa perspectiva de método, pois ao considerá-lo uma produção humana com origem nos meios de produção da nossa existência, admitimos sua gênese histórica. É por essa postura teórica que buscamos não apenas descrever o problema em sua superficialidade, ou pelo menos em sua aparência, mas também fazer uma análise explicativa, penetrando em seu interior, na sua dinâmica e gênese histórica. Por isso, não nos interessa descrever o preconceito presente nos livros infantis, partindo da perspectiva das diferenças humanas, por elas mesmas, como possíveis geradoras de preconceitos. O que pretendemos é investigar indícios sobre como o preconceito e as diferenças, como um processo, são tratados na literatura infantil, tendo por base sua condição histórica concreta. Isso significa questionar até que ponto as diferenças significativas são tratadas apenas do ponto de vista das condições naturais ou individuais dos sujeitos ou, ao contrário, são consideradas como processos históricos em relação com as questões históricas e culturais mais amplas. Sobre este método dialético, Vigotski (2007, p. 68) complementa dizendo que, “[...] estudar alguma coisa historicamente significa estudá-la no processo de mudança”.

Para o desenvolvimento da investigação foram analisadas 14 obras de literatura infantil que fazem parte do Acervo Complementar enviado aos três primeiros anos do ensino fundamental das escolas públicas pelo Programa Nacional do Livro Didático de 2013. As obras selecionadas que constituem o corpus de análise são: A economia de Maria (Andrade, 2010); A joaninha que perdeu as pintinhas (Paes, 2010); A rainha da bateria (Vila, 2009); Frederico Godofredo (Leão, 2010); Histórias de avô e avó (Nestrovski, 1998); Irmãos gêmeos (Yoo, 2008); Lilás, uma menina diferente (Whitcomb, 2011); Minha família é colorida (Martins, 2011); O silencioso mundo de Flor (França, 2011); Por que somos de cores diferentes? (Gil, 2006); Pretinho, meu boneco querido (Furtado, 2008); Quem é Glória? (Costta, 2011); Rupi! O menino das cavernas (Bush, 1997);

600 Educação \& Realidade, Porto Alegre, v. 41, n. 2, p. 591-612, abr./jun. 2016. 
Sofia, a andorinha (Taboada, 2011). A seleção dessas obras foi feita por meio da análise dos resumos das histórias presente no material produzido pelo PNLD e enviado aos professores junto com os acervos (Brasil, 2012).

A construção dos dados foi desenvolvida a partir de um protocolo elaborado por nós, estruturado em eixos, com base nas categorias presentes no referencial teórico desta pesquisa. Essa elaboração baseou-se em dois instrumentos de pesquisa: as categorias presentes na Grade Analítica sistematizadas por Amaral (1992) e também as categorias presentes no Manual para análise do personagem no texto desenvolvida por Rosemberg (1985). Nesse sentido, o protocolo foi dividido em cinco sessões: 1) dados catalográficos, 2) caracterização da história, 3) caracterização dos personagens, 4) caracterização da diferença. Ao final foi incluído um item aberto denominado 5) outros aspectos, visando contemplar questões pertinentes, que, por ventura, não correspondessem às categorias sistematizadas.

O processo de análise envolveu a transcrição e sucessivas leituras dos livros. Intercaladas a essas leituras, voltamos constantemente às referências bibliográficas que fundamentam tal pesquisa, o que permitiu sedimentar algumas impressões e dar lugar a outras, talvez mais elaboradas, que posteriormente emergiram nas análises. Assim, esse movimento de ir e vir dos materiais de análise ao referencial teórico foi um ponto fundamental durante todo o percurso.

Apresentamos a seguir os resultados encontrados em cada uma das sessões.

\section{O que Revelam as Obras Ofertadas pelo PNLD de 2013}

O processo de análise com relação à caracterização das histórias indica que a trama das histórias ocorre na vida cotidiana. Com base em Heller (2008), podemos considerar que é na vida cotidiana que se originam o preconceito e as diferenças, ou seja, nas atividades voltadas para a reprodução do indivíduo. As atividades desenvolvidas na vida cotidiana são objetivações genéricas-em-si e não exigem uma relação consciente entre o indivíduo e a vida cotidiana. Nesse mesmo eixo, pode-se perceber que a cidade foi a principal ambientação das narrativas. Como demonstra Cambi (1999), a partir da Modernidade, as cidades passam a ter cada vez mais importância, tornando-se o cenário principal das ações humanas na atualidade. Devemos considerar também o papel das cidades na formação do cidadão educado e civil, pois é nesse espaço onde principalmente são difundidas as normas de civilidade e comportamento social. Desse modo, as cidades assumem o papel de representantes dos padrões e comportamentos modernos, que incluem as boas maneiras e as formas adequadas de se relacionar. É possível supor que a significativa quantidade de obras que encontramos cuja ambientação acontece nas cidades pode ter relação justamente com o seu papel na 
difusão das normas de comportamentos sociais, bem como na circulação e comunicação das informações.

Quanto ao tipo de diferença, foram identificados cinco tipos nas obras analisadas: características comportamentais, deficiência, cor da pele, etnia e condições sociais. Quanto às diferenças retratadas nas histórias, o que percebemos foi que o maior número de obras $(5 \text { obras })^{1}$ apresentou as características comportamentais dos personagens para ilustrar a questão da diferença. Definimos como características comportamentais aquelas que se referem a comportamentos, atitudes ou jeito de ser dos personagens que pudessem ser geradoras da diferença.

Diante das histórias analisadas, percebemos que as características comportamentais são significadas como diferenças frente ao contexto social, conforme apresentado nas histórias. As diferenças entre os indivíduos existem e não são apenas estas que apareceram nas histórias. Isso nos faz questionar os motivos que levam determinado contexto social a eleger algumas características para serem significadas dessa maneira. A diferença referente à cor da pele apareceu em três obras², já a questão de diferenças étnicas ou raciais esteve presente em duas ${ }^{3}$. A deficiência em três obras ${ }^{4}$ foi apresentada como uma diferença presente no cotidiano, e as deficiências retratadas foram: deficiência auditiva, deficiência física (motora) e deficiência visual. Em apenas uma obra ${ }^{5}$, as condições sociais foram abordadas como promotora das diferenças.

Chama-nos a atenção que apenas uma obra aborde a questão das condições sociais relacionada à temática das diferenças e do preconceito dentre as obras analisadas. Como já observamos anteriormente, as diferenças humanas por elas mesmas não são promotoras do preconceito, pois o preconceito produzido nas relações sociais tem sua origem nas relações desiguais de produção da vida. Vieira (2008) também abordou esse assunto, afirmando que centrar o foco nas diferenças, sejam biológicas ou psicológicas, serve, na verdade, para encobrir a desigualdade, condição que não é natural, pois é socialmente construída. A desigualdade como tema presente na literatura infantil é tão importante quanto seu próprio processo, pois somente pela superação da alienação da vida cotidiana que a discriminação decorrente do preconceito pode ser eliminada.

Em relação à caracterização dos personagens, pode-se perceber que a maioria das obras apresenta o personagem principal como sendo uma criança (13 obras), de cor branca (10 obras), do sexo feminino (9 obras) e natureza humana (12 obras). Os estudos de Venâncio (2009) e outros pesquisadores anteriores a ela, mas pela mesma autora referenciados, apresentam a prevalência de personagens brancos e do sexo masculino na literatura infantil. Também encontramos a prevalência de personagens brancos em nossa pesquisa, o que confirma os resultados de pesquisas precedentes.

A análise do estereótipo nos permite discutir a própria personificação do preconceito, construída em nossa sociedade e que também 602 Educação \& Realidade, Porto Alegre, v. 41, n. 2, p. 591-612, abr./jun. 2016. 
é retratada na literatura infantil por meio dos tipos fixos, que, segundo Amaral (1992), se personificam nos papeis de herói, vítima e vilão das histórias. Frente ao exposto até aqui, podemos questionar: nas relações representadas na literatura infantil, em que as diferenças são significativas, que estereótipos são demarcados?

Em nossas análises percebemos que todos os personagens principais são retratados na forma de heróis, pois, mesmo diante das adversidades, encontram forças e procuram superar as situações ou os conflitos. Nas obras em que não se evidenciam questões de conflito em relação às diferenças, é a própria postura positiva do personagem que fica evidente, como se, mesmo sendo diferente, a exclusão ou o estranhamento que essa diferença gera nos outros personagens não provocasse nenhum tipo de incômodo. Chama a atenção o fato de não termos encontrado nenhum protagonista que personificasse o estereótipo de vilão nas tramas que envolvem as diferenças. Ao contrário dos resultados encontrados por Amaral (1992), em que foi usual a ocupação do lugar do vilão pelo personagem com deficiência, em nossa pesquisa a associação do personagem principal com o estereotipo de vilão não foi encontrada.

Nos últimos vinte anos, normatizações importantes, tanto no cenário mundial quanto nacional, podem ter influenciado nas mudanças de paradigmas e nas maneiras como as diferenças são percebidas, principalmente no que se refere ao espaço escolar. A Declaração de Salamanca (Brasil, 2014) elaborada em 1994 na Conferência Mundial sobre Necessidades Educativas Especiais, foi um marco em relação à inclusão por garantir o direito à educação independentemente das diferenças individuais. Depois desse evento, outras normatizações foram feitas no país a fim de dar subsídios para as práticas voltadas à educação inclusiva no Brasil. Pode-se inferir que, diferentemente dos achados de Amaral (1992), que realizou sua pesquisa antes de todas essas mudanças, o papel de herói dado aos personagens diferentes na literatura infantil atual reflete as mudanças que ocorreram no cenário educacional, na qual não existe mais lugar para um personagem vilão quando é abordada a temática das diferenças. Podemos também considerar que a prevalência de personagens heróis tenha a ver com a função pedagógica da literatura infantil, que apresenta o mundo como ele deve ser e não como ele é na realidade. Todos estes achados nos permitem levantar a hipótese de que o herói é o estereótipo hegemônico na literatura infantil analisada que trata as diferenças e que, diante de conflitos relacionados à diferença, os protagonistas das histórias são apresentados como vítimas da exclusão e heróis em seu papel de superação das dificuldades encontradas.

Quanto à caracterização das diferenças, foi possível verificar que doze obras analisadas, ou seja, a maioria, apresentam diferenças significativas em suas histórias, e em duas obras são retratadas nos textos apenas diferenças simples. Embora tenha sido possível identificar com bastante clareza as diferenças significativas, percebemos que quando 
se fala em diferenças é usual misturá-las, e com isso diferenças simples e significativas se confundem nas histórias. Sendo assim, diferentes gostos ou preferências se misturam às diferenças significativas como as que envolvem a questão étnica ou de gênero, o que pode ser um indício da banalização do tema. O trecho a seguir ilustra bem essa confusão:

Minha mãe sempre diz que as pessoas são diferentes umas das outras e isso é muito bom. Já pensaram se todas as pessoas pensassem a mesma coisa, se vestissem iguais, gostassem das mesmas coisas, da mesma comida, tivessem a mesma cor, a mesma raça, fossem do mesmo sexo, torcessem pelo mesmo time de futebol, tivesse a mesma religião. O mundo seria muito sem graça, não seria? (Furtado; Pestili, 2008, p. 38).

A qualidade da diferença na literatura infantil também foi analisada. Percebemos que em cinco obras ${ }^{6}$ as diferenças são retratadas como positivas. No contexto das histórias, as diferenças são positivas enquanto não causam conflitos ou sofrimentos ao diferente ou ainda quando o personagem é valorizado pela própria diferença. Na maioria das histórias, em nove obras ${ }^{7}$ analisadas, as diferenças são apresentadas como sendo inicialmente algo negativo. Em apenas uma ${ }^{8}$ delas essa caracterização permanece assim, sendo que nas demais (oito), a característica negativa é superada por meio dos esforços do personagem principal - o herói. Isso assinala o aspecto positivo da diferença. Podemos ainda perceber que em nenhuma das obras analisadas as diferenças são retratadas como sendo neutras. Amaral (1992) obteve resultados semelhantes e assim como nós, que não encontramos obras que retratassem a diferença como neutra, também em sua pesquisa ocorreu uma baixa pontuação para esta categoria. Uma possível explicação para isso pode ser o fato de que a neutralidade não é um atributo inerente a qualquer evento que fuja ao esperado, ao usual. Nesse sentido, a diferença mobiliza, segundo a própria Amaral (1992), desorganiza e ameaça quem se defronta com ela.

Além do caráter qualitativo da diferença, essa característica de superação das dificuldades pelos esforços dos personagens, remete às discussões a respeito da meritocracia. A igualdade de oportunidades está no centro do ideal meritocrático, que reconhece publicamente aqueles que se sobressaem a partir de seus talentos e esforços pessoais (Santos, 2011). Conforme Santos (2011, p. 47), “[...] o desempenho é resultado de processos e mecanismos intrínsecos ao ser humano, de ordem mais psicológica do que social, ou seja, é mais um produto individual do que social”. Portanto, deve-se dizer que o ideal meritocrático é baseado na crença da igualdade de oportunidades para todos, na qual, independentemente de suas origens, cada um pode pelos seus esforços chegar ao topo da pirâmide social. As histórias analisadas estão marcadas pela ideologia dos méritos, na qual o personagem é apresentado como herói, que pelos seus esforços individuais supera as diferenças e as dificul- 
dades provocadas por elas. Nesse sentido, mais uma vez verificamos que o individual se sobrepõe ao social no que diz respeito às diferenças. Percebe-se que, de acordo com o ideal dos méritos, as origens das diferenças são fundamentais nesse processo, pois os personagens possuem iguais oportunidades que podem ser superadas por meio do empenho individual. Essa constatação vai na direção oposta do que discutimos até aqui, pois individualiza questões que decorrem da estrutura da nossa sociedade, desresponsabilizando assim a sociedade mais ampla pelas formas de lidar com as diferenças e a produção de preconceitos. Essa tendência meritocrática confirma nossa percepção a respeito de como as diferenças são abordadas nas histórias infantis, ou seja, o foco recai sobre as questões naturais e individuais, sem com isso ter que discutir as desigualdades sociais, estas sim relacionadas à produção de preconceitos.

Em relação à origem das diferenças, os dados apontam que em seis obras ${ }^{9}$ as ações ou comportamentos individuais dos personagens dão origem às diferenças apresentadas; em outras seis histórias ${ }^{10}$, a origem das diferenças tem relação com causas naturais, e mais uma vez destacamos que as condições sociais e históricas estão presentes em apenas duas obras ${ }^{11}$, como forma de justificar a origem das diferenças e dos preconceitos vividos pelos personagens.

Percebemos que nas histórias em que as características comportamentais deram origem às diferenças, as ações ou comportamentos diferentes não são comportamentos negativos, como brigar, bater ou, por exemplo, roubar. Os personagens retratados como diferentes dos demais apresentam comportamentos diferenciados, porém positivos, considerando que, na maioria das vezes, acabam sendo aceitos e até valorizados pelas diferenças.

Nas obras em que a origem das diferenças é justificada por causas naturais, podemos perceber dois agrupamentos. De um lado, estão histórias de crianças com deficiências e por isso a origem da diferença remete à própria condição de incapacidade. De outro, são histórias que justificam a origem das diferenças pela cor da pele de cada indivíduo.

Os movimentos gerados pelas diferenças foi outra questão investigada por nós no protocolo, com base na ideia de que o diferente mobiliza uma ação, que pode ser no sentido de aproximar ou afastar a diferença em questão. Segundo Amaral (1994), sob o ponto de vista psíquico, as diferenças significativas não passam em brancas nuvens, pois elas, ao representar o que foge ao esperado, ao simétrico, ao belo, ao eficiente e ao perfeito, acabam desorganizando, ameaçando e mobilizando uma ação.

Das obras analisadas, seis ${ }^{12}$ apresentaram movimentos de afastamento em relação à diferença retratada. Além do afastamento, em três destas obras a diferença também causou repulsa e isolamento do personagem a qual foi atribuída a diferença. Em duas ${ }^{13}$ dessas obras, iden- 
tificamos um movimento de ataque e em outra ${ }^{14}$ a personagem diferente foi abandonada.

A última categoria que analisa as diferenças busca estabelecer relações entre as diferenças retratadas nas obras e os diferentes desfechos dados às histórias. Podemos perceber que a aceitação ativa é a categoria mais frequente nos desfechos das obras analisadas, pois em dez obras ${ }^{15}$ identificamos esta modalidade. Nosso resultado vai ao encontro de Amaral (1992) que em sua pesquisa também identificou a aceitação ativa como a modalidade de desfecho mais frequente nas obras analisadas. Segundo a autora, o caminho que leva a um desfecho de aceitação passa inicialmente pela acolhida da diferença, que pressupõe o reconhecimento do fato, seu dimensionamento, e consequentemente a metabolização das implicações correspondentes. Somente a partir disso é possível aos personagens superar os limites impostos por dadas condições. E foi isso que encontramos nas obras analisadas com esse tipo de desfecho: personagens que reconhecem sua diferença, dimensionam, metabolizam e superam seus limites diante das diferenças ou das dificuldades geradas por elas.

Sem desconsiderar a discussão feita por Amaral (1992), é possível ainda fazer outra reflexão a respeito da aceitação ativa presente nos desfechos das histórias. Será que a aceitação da diferença, tão recorrente nessas obras, não está mais ligada a uma atitude conformadora da realidade desigual própria da sociedade de classes, que busca explicar as diferenças sociais pelas diferenças individuais? Lembramos o que Heller (2008) diz sobre a origem dos preconceitos. Segundo a autora, os preconceitos são produtos principalmente das classes dominantes e chama a atenção para o fato de que, mesmo quando as classes dominantes pretendem, na esfera do para-si (como é o caso da literatura infantil), propagar uma imagem de mundo isenta de preconceitos, elas estão tão somente procurando manter a coesão de uma estrutura social que lhe beneficia.

Entendemos a eliminação da diferença, a partir de nossas análises e referenciais teóricos, como o desfecho mais preconceituoso das histórias e está presente em duas ${ }^{16}$ delas. Nas obras com esse desfecho fica evidente que a condição de diferente é promotora de sofrimento e tristeza e somente com a eliminação da diferença que é possível ser feliz. Desse modo, o preconceito e a exclusão são, com isso, perpetuados e confirmados.

Na última sessão do protocolo, questões referentes ao preconceito e à literalidade da obra também foram analisadas. À medida que avançávamos na análise das obras selecionadas, percebemos que a literalidade da obra poderia tomar proporções maiores do que inicialmente pensávamos. Sobre esse aspecto do texto literário, vale lembrar que se trata de obras que deixam brechas para serem preenchidas pelas crianças, num movimento que permite ao leitor aprender, refletir, comparar, questionar, investigar, transformar e adquirir cultura, ao entrar em 
contato com as mais diferentes visões de mundo. Segundo Bragatto Filho (1995, p. 15), os textos literários “[...] possuem determinadas lacunas ou espaços vagos ou nebulosos que são descobertos e preenchidos pelos leitores".

Diversas foram as obras que apresentaram outras possibilidades por meio de sua realização literária. Nesse sentido, vemos duas possibilidades de realização da literatura infantil. Por um lado pode se realizar, como mais um instrumento de alienação que se articula às abordagens rotineiras de reprodução ideológica da sociedade de classes. Isso quer dizer que, de um lado, abordar as diferenças e o preconceito na literatura infantil pode servir como instrumento de alienação e conformação à realidade posta. Por outro, quando a obra permite que o leitor crie outros sentidos ao tomar suas próprias experiências como referência, nesse caso pode servir como instrumento de superação da alienação da vida cotidiana.

A estrutura do protocolo elaborado para esta pesquisa permite sistematizar principalmente a caracterização das diferenças presente nas obras selecionadas. No entanto, queríamos saber também se o preconceito aparece nessas histórias e de que forma isso ocorre. Perguntávamos-nos se o preconceito seria citado, que justificativas eram dadas a ele, ou ainda se encontraríamos rastros de preconceito que não foram contemplados pelas demais sessões do protocolo até pela objetividade que caracteriza este instrumento.

Pode-se perceber que o preconceito esteve presente em diversas obras objetivado pela naturalização dos papeis masculinos e femini$\operatorname{nos}^{17}$, pelo apelido dado ao personagem que ao atenuar a diferença expressa o preconceito velado ${ }^{18}$, pela paparicação em relação às pessoas com deficiência ou ainda pela generalização indevida ${ }^{19}$, ou seja, tornar a pessoa como um todo deficiente. Nossos achados reforçam o que Heller (2008) alerta há alguns anos: para o fato de que não é possível eliminar o preconceito na sociedade capitalista, pois trata-se de um processo histórico inerente às relações de produção da vida. Entretanto, é possível pela desalienação da vida cotidiana superar a expressão discriminatória do preconceito.

Por outro lado, percebemos em diversos momentos histórias que vão em direção oposta à reprodução do preconceito. Na obra Sofia, $a$ andorinha escrita por Almudena Taboada, a personagem principal é uma andorinha com deficiência visual que aprende a ver a vida pelos outros sentidos. Ela tem aulas com seu professor Braile Coruja que lhe ensina a reconhecer cheiros e sons. Certa vez, encontra um amigo chorando pois se perdeu na floresta perto do povoado em que vive. Sofia se oferece para acompanhar o menino até sua casa. Para a surpresa do menino, mesmo Sofia não conseguindo enxergar reconhece o caminho de volta pelos sons e cheiros. Na análise da obra, chamou-nos atenção a forma como o texto trata a deficiência visual de Sofia. O trecho a seguir 
ilustra o que queremos dizer: "Braile é seu professor de sons e cheiros, porque Sofia tem os olhinhos cegos" (Taboada, 2011, p. 10).

Essa passagem escrita com tanta simplicidade, de forma autêntica, diz aos leitores o que realmente Sofia tem, os olhos cegos, pois não a toma como uma pessoa cega, visto que existem tantas outras formas de ver o mundo. E assim Sofia apreende o mundo, onde "[...] o verde tem gosto de grama e de bala de menta. $\mathrm{O}$ amarelo tem gosto de trigo ou de quindim. $\mathrm{O}$ azul tem gosto de água do rio e de doce de anis" (Taboada, 2011, p.11-13).

\section{Considerações Finais}

A partir das reflexões feitas até aqui, uma pergunta torna-se inevitável: é possível romper com este ciclo que envolve as desigualdades, a alienação e os preconceitos? Como fazer? Segundo Heller (2008, p. 83), “[...] os preconceitos não podem ser totalmente eliminados do desenvolvimento social"; no entanto, é possível "[...] eliminar a organização dos preconceitos em sistema, sua rigidez - o que é mais essencial - a discriminação efetivada pelos preconceitos". A respeito do como fazer, um possível caminho é indicado pela autora (Heller, 2008, p. 88) ao afirmar que devemos construir nossa "[...] capacidade de julgar corretamente o singular", para então sermos "[...] capazes de nos libertar de nossos preconceitos e de reconquistar sempre a nossa relativa liberdade de escolha".

Com isso, pensamos que a literatura infantil pode ter um papel fundamental na ampliação das experiências infantis em questões referentes ao preconceito e ao significativamente diferente. Os livros infantis, mais do que apresentar as diferenças humanas no âmbito das características individuais dos sujeitos e com isso confirmar a ideia de que são elas (as diferenças) por si mesmas que produzem preconceito, podem contribuir para a compreensão do preconceito como sendo resultante da relação do indivíduo com a cultura, situado historicamente, e por isso mesmo dinâmico e passível de mudanças.

Uma síntese das análises realizadas evidencia que as histórias que tratam das diferenças apresentam sua trama na vida cotidiana, que é a principal esfera onde se originam o preconceito e as diferenças. Os tipos de diferenças encontrados foram em relação às características comportamentais, deficiência, condições sociais, cor da pele e etnia. Os personagens ilustrados nas histórias são retratados em sua maioria por crianças de cor branca, do sexo feminino e natureza humana e são personagens que carregam o estereótipo de herói que, diante das adversidades provocadas em tese pelas diferenças, encontram forças para superar as situações e os conflitos que porventura enfrentam. Permeadas pela ideologia dos méritos, o personagem herói pelos seus esforços supera as diferenças e as dificuldades encontradas. Nesse sentido, ve-

608 Educação \& Realidade, Porto Alegre, v. 41, n. 2, p. 591-612, abr./jun. 2016. 
rifica-se que o individual se sobrepõe ao social, desresponsabilizando assim a sociedade mais ampla pelas diferenças e preconceitos.

As diferenças abordadas nas histórias tratam-se, em grande parte, de diferenças significativas, ou seja, aquelas que são mais complexas e que podem causar um clima conflitivo. No entanto, quando apresentadas nas obras, as diferenças simples e significativas acabam sendo tratadas da mesma forma, sem distinções.

Percebe-se nas histórias também uma tendência de apresentar as diferenças inicialmente como algo negativo, mas que, pelos esforços dos personagens, passam a ser positivas e por isso aceitas pelos demais. Desse modo, constata-se que a neutralidade não faz parte das histórias que tematizam as diferenças, já que elas mobilizam na direção de um movimento que pode ser tanto de afastamento, quanto de aproximação.

As origens das diferenças identificadas são em sua maioria por causas individuais ou causas naturais, poucas obras problematizam a questão das diferenças pela via das condições sociais. Apesar disso, percebemos que as obras de literatura infantil que tematizam tais questões podem, em sua realização literária, contribuir para que o leitor crie outros sentidos às situações que envolvem o preconceito, tomando como referência as próprias experiências. Isso quer dizer que abordar as diferenças e o preconceito na literatura infantil pode servir tanto como um instrumento de alienação e conformação, quanto um convite ao leitor para criar novos sentidos e superar a alienação da vida cotidiana.

É necessário discutir as diferenças humanas tendo como ponto de partida sua dimensão histórica, considerando que elas são objetivadas nos processos desiguais da produção da existência humana. Enquanto as discussões não forem pautadas nesses termos, ou seja, enquanto se falar das diferenças de forma superficial, explicadas pelas dessemelhanças (diferenças) individuais, servirão apenas para reforçar a passividade, a obediência e a submissão que atende às necessidades de uma ordem social injusta e desigual e as reforça.

Nesse sentido, valer-se da literatura infantil para falar das diferenças, nesses termos, apazigua conflitos servindo apenas como instrumento gerador e mantenedor de desigualdades.

Pensando nas possibilidades que decorrem desta pesquisa, podemos afirmar que é preciso proporcionar às crianças a capacidade de julgar corretamente o singular. A literatura infantil, em sua realização literária, pode ter papel fundamental nesse processo, para que as crianças não apenas reproduzam os preconceitos construídos historicamente, como também, quem sabe, possam exercitar sua relativa liberdade de escolha. 


\section{Notas}

1 A economia de Maria; Frederico Godofredo; Irmãos Gêmeos; Lilás, uma menina diferente e Rupi, o menino das cavernas.

2 A joaninha que perdeu as pintinhas; Minha família é colorida e Por que somos de cores diferentes?

3 Histórias de avô e avó; Pretinho, meu boneco querido.

4 O silencioso mundo de Flor; Quem é Glória? e Sofia, a andorinha.

5 A rainha da bateria.

6 A economia de Maria; Frederico Godofredo; Por que somos de cores diferentes?; Quem é Glória? e Sofia, a andorinha.

7 A joaninha que perdeu as pintinhas; A rainha da bateria; Histórias de avô e avó; Irmãos gêmeos; Lilás, uma menina diferente; Minha família é colorida; O silencioso mundo de Flor; Pretinho, meu boneco querido e Rupi! O menino das cavernas.

8 A joaninha que perdeu as pintinhas.

9 A economia de Maria; A joaninha que perdeu as pintinhas; Frederico Godofredo; Irmãos gêmeos; Lilás, uma menina diferente e Rupi! O menino das cavernas.

10 Histórias de avô e avó; Minha família é colorida; O silencioso mundo de Flor; Por que somos de cores diferentes?; Quem é Glória? e Sofia, a andorinha.

11 A rainha da bateria e Pretinho, meu boneco querido.

12 A joaninha que perdeu as pintinhas; A rainha da bateria; Histórias de avô e avó; Lilás, uma menina diferente; Pretinho, meu boneco querido; Rupi! O menino das cavernas.

13 Irmãos gêmeos; Pretinho, meu boneco querido.

14 A joaninha que perdeu as pintinhas.

15 A economia de Maria; A rainha da bateria; Frederico Godofredo; Histórias de avô e avó; Lilás, uma menina diferente; Minha família é colorida; Por que somos de cores diferentes?; Pretinho, meu boneco querido; Quem é Glória?; Sofia, a andorinha.

16 A joaninha que perdeu as pintinhas e Irmãos gêmeos.

17 Histórias de avô e avó.

18 Pretinho, meu boneco querido.

19 Quem é Glória.

\section{Referências}

AMARAL, Lígia Assumpção. Espelho Convexo: o corpo desviante no imaginário coletivo pela voz da Literatura Infanto-Juvenil. 1992. 410f. Tese (Doutorado em Psicologia) - Programa de Pós-Graduação em Psicologia, Universidade de São Paulo, São Paulo, 1992.

AMARAL, Lígia Assumpção. Corpo desviante: olhar perplexo. Psicologia USP, São Paulo, v. 5, n. 1-2, p. 245-268, 1994.

610 Educação \& Realidade, Porto Alegre, v. 41, n. 2, p. 591-612, abr./jun. 2016. 
AMARAL, Lígia Assumpção. Sobre crocodilos e avestruzes: falando de diferenças físicas, preconceitos e sua superação. In: AQUINO, Júlio Groppa (Org.). Diferenças e Preconceito na Escola: alternativas teóricas e práticas. São Paulo: Summus, 1998. P. 11-30.

ANDRADE, Telma Guimarães Castro. A Economia de Maria. Il. Silvana Rando. São Paulo: Editora do Brasil, 2010.

ARIÈS, Philippe. História Social da Criança e da Família. 2. ed. Tradução de Dora Flaksman. Rio de Janeiro: LTC, 2012.

BRAGATTO FILHO, Paulo. Pela Leitura Literária na Escola de $1^{\circ}$ Grau. São Paulo: Ática, 1995.

BRASIL. Declaração de Salamanca e Linha de Ação Sobre Necessidades Educativas Especiais. Brasília: UNESCO, 1994. Disponível em: <http://portal.mec. gov.br/seesp/arquivos/pdf/salamanca.pdf $>$. Acesso em: 10 jun. 2014.

BRASIL. Ministério da Educação. Acervos Complementares: alfabetização e letramento nas diferentes áreas do conhecimento. Brasília: MEC, 2012, p. 140.

BUENDGENS, Jully Fortunato. O Preconceito e as Diferenças na Literatura Infantil: um estudo de caso com base na Teoria Histórico-Cultural. 2014. 171f. Dissertação (Mestrado em Educação) - Programa de Pós Graduação em Educação, Universidade Federal de Santa Catarina, Florianópolis, 2014.

BUSH, Timothy. Rupi! O Menino das Cavernas. São Paulo: Brinque-Book, 1997. CADEMARTORI, Ligia. O que é Literatura Infantil. 2. ed. São Paulo: Brasiliense, 2010.

CAMBI, Franco. História da Pedagogia. Tradução de Álvaro Lorencini. São Paulo: Fundação Editora UNESP, 1999.

COSTTA, Silvio. Quem é Glória? Il. Marta Neves. Sabará: Dubolsinho, 2011.

DUARTE, Newton. Educação Escolar, Teoria do Cotidiano e a Escola de Vigotski. 4. ed. São Paulo: Autores associados, 2007.

DUARTE, Newton. Sociedade do Conhecimento ou Sociedade das Ilusões? Quatro ensaios crítico-dialéticos em filosofia da educação. São Paulo: Autores Associados, 2008.

FRANÇA, Cecília Cavalieri. O Silencioso Mundo de Flor. Il. André Persechini. Belo Horizonte: Fino Traço, 2011.

FURTADO, Maria Cristina. Pretinho, Meu Boneco Querido. Il. Ellen Pestili. São Paulo: Editora do Brasil, 2008.

GIL, Carmen. Por que Somos de Cor Diferentes? Il. Luis Filella. São Paulo: Girafinha, 2006.

HELLER, Agnes. O Cotidiano e a História. 8. ed. Tradução de Carlos Nelson Coutinho e Leandro Konder. São Paulo: Paz e Terra, 2008.

LEÃO, Liana. Frederico Godofredo. Il. Márcia Széliga. São Paulo: Elementar, 2010.

LEONTIEV, Aléxis. O Desenvolvimento do Psiquismo. Lisboa: Livros Horizonte, 2004.

MARTINS, Georgina. Minha Família é Colorida. Il. Maria Eugênia. São Paulo: Comboio de Corda, 2011.

NESTROVSKI, Arthur. Histórias de Avô e Avó. Il. Maria Eugênia. São Paulo: Companhia das Letras, 1998. 
PAES, Ducarmo. A Joaninha que Perdeu as Pintinhas. Il. Jefferson Pereira Galdino. São Paulo: Best Book, 2010.

PINO, Angel. A psicologia concreta de Vigotski: implicações para a educação. In. PLACCO, Vera Maria Nigro de Souza (Org.). Psicologia \& Educação: revendo contribuições. São Paulo: EDUC, 2000. P. 33-61.

PINO, Angel. As Marcas do Humano: às origens da constituição cultural da criança na perspectiva de Lev S. Vigotski. São Paulo: Cortez, 2005.

ROSEMBERG, Fúlvia. Literatura Infanto-Juvenil e Ideologia. São Paulo: Global, 1985.

SANTOS, Marcelo Barbosa. Mérito e Racismo: "tudo junto e misturado". 2011. 203f. Dissertação (Mestrado em Educação) - Universidade do Estado do Rio de Janeiro, Rio de Janeiro, 2011.

TABOADA, Almudena. Sofia, a Andorinha. Il. Ana López Escrivá. Tradução de Maísa Kawata. São Paulo: Comboio de Corda, 2011.

VENÂNCIO, Ana Carolina Lopes. Literatura Infanto-Juvenil e Diversidade. 2009. 228f. Dissertação (Mestrado em Educação) - Programa de Pós-Graduação em Educação, Universidade Federal do Paraná, Curitiba, 2009.

VIEIRA, Renata de Almeida. O Preconceito como Objetivação Humana. 2008. 142f. Dissertação (Mestrado em Educação) - Programa de Pós Graduação em Educação, Universidade Estadual de Maringá, Maringá, 2008.

VIGOTSKI, Liev Semionovich. Pensamento e Linguagem. Tradução de Jeferson Luiz Camargo. São Paulo: Martins Fontes, 1989.

VIGOTSKI, Liev Semionovich. A formação Social da Mente: o desenvolvimento dos processos psicológicos superiores. 7. ed. Tradução de José Cipolla Neto, Luís Silveira Barreto, Solange Castro Afeche. São Paulo: Martins Fontes, 2007.

VIGOTSKI, Liev Semionovich. Imaginação e Criação na Infância: ensaio psicológico. Tradução de Zoia Prestes. São Paulo: Ática, 2009.

VILA, Martinho da. A Rainha da Bateria. Il. Marcelo D’Salete. São Paulo: Lazuli Editora, 2009.

WHITCOMB, Mary. Lilás, uma Menina Diferente. Il. Tara Calahan King. São Paulo: Cosac Naify, 2011.

YOO, Young So. Irmãos Gêmeos. Il. Young Mi Park. São Paulo: Callis, 2008.

ZILBERMAN, Regina. A Literatura Infantil na Escola. 11. ed. São Paulo: Global, 2003.

Jully Fortunato Buendgens é graduada em Psicologia pela Universidade da Região de Joinville (2012) e Mestre em Educação pela Universidade Federal de Santa Catarina (2014), na Linha Educação e Infância.

E-mail: jfb0104@hotmail.com

Diana Carvalho de Carvalho é doutora em Educação pela Universidade Federal de São Paulo (2014) e Professora do Departamento de Metodologia do Ensino e do Programa de Pós-Graduação em Educação - UFSC.

E-mail:dianacc@terra.com.br 